\title{
A 12-week supplementation with quercetin does not affect natural killer cell activity, granulocyte oxidative burst activity or granulocyte phagocytosis in female human subjects
}

\author{
Serena A. Heinz ${ }^{1}$, Dru A. Henson ${ }^{1}$, David C. Nieman ${ }^{2} *$, Melanie D. Austin ${ }^{2}$ and Fuxia Jin ${ }^{2}$ \\ ${ }^{1}$ Department of Biology, Appalachian State University, Boone, NC, USA \\ ${ }^{2}$ Department of Health, Leisure, and Exercise Science, Appalachian State University, Boone, NC, USA
}

(Received 28 October 2009 - Revised 22 March 2010 - Accepted 24 March 2010 - First published online 26 May 2010)

Quercetin, a flavonoid found in fruits and vegetables, is a strong antioxidant with anti-inflammatory, antimicrobial and immune-modulating properties. The purpose of the present study was to investigate the effects of long-term quercetin supplementation on innate immune function and inflammation in human subjects. Female subjects ( $n$ 120; aged 30-79 years) were recruited from the community and randomised to one of three groups, with supplements administered using double-blinded procedures: $500 \mathrm{mg}$ quercetin/d $(n$ 38), $1000 \mathrm{mg}$ quercetin/d $(n$ 40) or placebo $(n$ 42). Subjects ingested two soft chew supplements twice daily during the 12-week study period. Fasting blood samples were obtained pre- and post-study and were analysed for plasma quercetin, IL-6, TNF- $\alpha$ and leucocyte subset cell counts. Natural killer cell activity (NKCA) and lymphocyte subsets were assessed in a subset of seventy-four subjects. Granulocyte oxidative burst activity (GOBA) and phagocytosis were assessed in sixty-four subjects. Eighteen subjects had overlapping data. Quercetin supplementation at two doses compared with placebo increased plasma quercetin (interaction effect; $P<0.001$ ) but had no significant influence on blood leucocyte subsets, plasma IL-6 or TNF- $\alpha$ concentration, NKCA, GOBA or phagocytosis. NKCA was inversely correlated with BMI $(r-0.25 ; P=0.035)$ and body fat percentage $(r-0 \cdot 38 ; P=0.001)$, and positively correlated with self-reported physical fitness level $(r 0.24 ; P=0.032)$. In summary, results from the present double-blinded, placebo-controlled, randomised trial indicated that quercetin supplementation at 500 and $1000 \mathrm{mg} / \mathrm{d}$ for 12 weeks significantly increased plasma quercetin levels but had no influence on measures of innate immune function or inflammation in community-dwelling adult females.

Quercetin: Immune function: Natural killer cells: Neutrophils

Polyphenolic compounds are found in a wide variety of human foods, including fruits, vegetables, nuts, seeds, tea and honey ${ }^{(1)}$. Flavonoids are a large and complex group of polyphenols that share a basic three-ring chemical structure, with two aromatic centres and a central oxygenated heterocyclic ring ${ }^{(2)}$. The most prominent flavonoids in fruits and vegetables are flavonols, and, of these, quercetin (3,3',4',5,7-pentahydroxyflavone) is the most commonly consumed in the human $\operatorname{diet}^{(2)}$. The physiological effects of dietary flavonols such as quercetin are of current interest due to their in vitro anti-oxidative ${ }^{(3,4)}$, anti-inflammatory ${ }^{(5,6)}$ and anti-pathogenic ${ }^{(7,8)}$ activities.

Total dietary flavonol intake estimates for US adults range from 13 to $22 \mathrm{mg} / \mathrm{d}$, with quercetin representing about $75 \%{ }^{(9,10)}$. Following absorption from food or supplements, elimination of quercetin is slow, with a reported half-life ranging from 11 to $28 \mathrm{~h}^{(2)}$. Quercetin conjugates are widely distributed in the organ tissues of rats after supplementation, where they may be biologically active ${ }^{(11)}$. Despite earlier concerns, long-term supplementation with high doses of quercetin has not been linked to any adverse effects in rodents or human subjects ${ }^{(12,13)}$. Moreover, epidemiological studies have positively correlated flavonoid intake with decreased incidence of $\mathrm{CHD}^{(14)}$ and common human cancers ${ }^{(15)}$. The potential beneficial health effects of supplementation with quercetin deserve further attention and are the subject of the present study.

In vitro and animal studies indicate that quercetin supplementation has the potential to exhibit multiple immunomodulatory effects including augmentation of neutrophil chemotaxis and respiratory burst activity ${ }^{(16)}$, macrophage function $^{(17,18)}$ and natural killer (NK) cell lytic activity ${ }^{(18,19)}$. $\mathrm{NK}$ cells and granulocytes are dominant players in early host defence against pathogens; thus, their potential augmentation by quercetin could have important health benefits. NK cells, which comprise $10-15 \%$ of circulating lymphocytes in humans, play a central role in initial host resistance to viral, bacterial and parasitic infections due to their ability to lyse target cells without prior sensitisation ${ }^{(20,21)}$. Also critical to optimal cellular immune function are the phagocytic and microbicidal activities of granulocytes, of which polymorphonuclear leucocytes, or neutrophils, are the most abundant. Neutrophils are swiftly recruited to infection sites, where they engulf pathogens in a process called phagocytosis ${ }^{(22)}$. Phagocytosis, in turn, stimulates the production of reactive

Abbreviations: FITC, fluorescein isothiocyanate; GOBA, granulocyte oxidative burst activity; NK, natural killer; NKCA, natural killer cell activity; Q-500, 500 mg quercetin/d; Q-1000, $1000 \mathrm{mg}$ quercetin/d; RPMI, Roswell Park Memorial Institute.

* Corresponding author: Professor David C. Nieman, email niemandc@appstate.edu 
oxygen species. This respiratory burst, also known as the oxidative burst, is responsible for the oxygen-dependent intracellular killing of ingested microbes. Several animal and in vitro studies have shown that quercetin augments NK cell activity (NKCA) as well as granulocyte oxidative burst activity (GOBA) and phagocytosis ${ }^{(16,18,19)}$, but few studies have examined the effects of quercetin supplementation on innate immune function in human subjects.

Two short-term human studies previously conducted by our laboratory found no differences in NKCA or GOBA following ingestion of aglycone quercetin at $1000 \mathrm{mg} / \mathrm{d}$ for 3 weeks compared with placebo ${ }^{(23,24)}$, although one study found that quercetin supplementation reduced the incidence and severity of respiratory infections in endurance athletes after $3 \mathrm{~d}$ exhaustive exercise ${ }^{(24)}$. However, these studies were primarily focused on quercetin's acute effects on post-exercise immune function perturbations in highly trained athletes, and as such were limited in their application to non-athletes. The present study seeks to examine the chronic effects of quercetin consumption on innate immune function in the general population. A secondary objective of the study was to assess the influence of quercetin on markers of inflammation.

Chronically elevated inflammatory cytokines such as IL-6 and TNF- $\alpha$ have been correlated with increased risk of rheumatoid arthritis ${ }^{(25)}$ and $\mathrm{CHD}^{(26)}$. Quercetin, which has been shown to exert strong in vitro anti-inflammatory effects, acts specifically through the NF- $\kappa \mathrm{B}$ signalling pathway to decrease expression of IL-6 and TNF- $\alpha^{(5,6)}$. Supplementation with quercetin could potentially be used to reduce chronic expression of these inflammatory cytokines, thereby lowering disease risk. Although quercetin exerts strong in vitro antiinflammatory effects, few supplementation trials have been conducted to examine the effects of quercetin supplementation on circulating markers of inflammation. A recent study by Egert et al. investigated whether $150 \mathrm{mg}$ quercetin/d for 6 weeks would decrease plasma TNF- $\alpha$ in overweight and obese subjects, but no such effect was found ${ }^{(27)}$. The authors postulated that the dosage of quercetin used in their study was insufficient to exert significant anti-inflammatory effects in the blood compartment. The present study will examine whether longer-term supplementation with quercetin at higher dosages has an influence on markers of inflammation in adult female subjects.

It is currently unknown whether long-term quercetin supplementation exhibits an immunomodulatory effect in humans, or whether these potential effects are dose-dependent. The objective of the present study was to measure the influence of 12-week aglycone quercetin supplementation in two doses $(500$ and $1000 \mathrm{mg} / \mathrm{d})$ on measures of innate immune function (NKCA, GOBA and granulocyte phagocytosis) and markers of inflammation (plasma IL-6 and TNF- $\alpha$ ) in adult, community-dwelling female subjects. Dosages and supplementation periods used were chosen based on animal data and prior work in our laboratory ${ }^{(28,29)}$.

\section{Methods}

\section{Subjects}

A total of 120 females, aged 30-79 years, were recruited via mass advertising. Subjects had to be healthy and non-institutionalised, and women were excluded if pregnant or lactating. Subjects agreed to avoid any other supplements containing quercetin; no other restrictions were placed on diet, supplement usage or medications. The present study was conducted according to the guidelines laid down in the Declaration of Helsinki and all procedures involving human subjects were approved by the institutional review board of Appalachian State University. Written informed consent was obtained from all subjects.

\section{Research design}

Subjects were randomised to one of three groups: $500 \mathrm{mg}$ quercetin/d (Q-500; $n$ 38), $1000 \mathrm{mg}$ quercetin/d (Q-1000; $n 40$ ) or placebo ( $n$ 42). Supplements were administered utilising double-blinded procedures. Subjects ingested two soft chew supplements twice daily (upon awakening, and between 14.00 hours and the last meal of the day) during the 12-week study period. Supplements were prepared by Nutravail Technologies (Chantilly, VA, USA) with Quercegen Pharma (Newton, MA, USA), and were soft, individually wrapped chews $(5.3 \mathrm{~g} /$ piece $)$ that contained either 125 or $250 \mathrm{mg}$ quercetin, 125 or $250 \mathrm{mg}$ vitamin $\mathrm{C}$ (ascorbic acid and sodium ascorbate), 5 or $10 \mathrm{mg}$ niacin, and $20 \mathrm{kcal}(84 \mathrm{~kJ})$ of sugars in a carnauba wax, soya lecithin, maize starch, glycerine and palm oil base coloured with Food, Drug and Cosmetic Act (FD\&C) yellow no. 5 and no. 6. A series of HPLC measurements was conducted to determine that the amount of quercetin in each chew was stable and accurate. Placebo supplements were prepared in the same way minus the quercetin, vitamin $\mathrm{C}$ and niacin. Data from Quercegen Pharma (unpublished results, personal communication) indicate that bioavailability of quercetin is enhanced with vitamin $\mathrm{C}$ and niacin; hence, the present study tested whether or not soft chews with or without the combination of quercetin, vitamin $\mathrm{C}$ and niacin had an influence on the outcome measures. Subjects started supplementing after the first blood sample and continued for 12 weeks. At 2 weeks before the first laboratory visit for the study, subjects provided demographic and lifestyle habit information via a survey posted on the web using SurveyMonkey. com (Portland, OR, USA). Information on dietary patterns was obtained through a semi-quantitative FFQ for food groups including fruit, vegetables, cereals, meat, dairy and fat. Exercise habits were assessed through answers to categorical questions dealing with both leisure-time and work activities. Physical fitness levels were self-reported using a ten-point Likert scale, with one corresponding to low fitness and ten to high fitness. Subject height was measured with a stadiometer, and BMI and body composition were determined using a Tanita bioelectrical impedance scale (Tanita, Arlington Heights, IL, USA). Before and after the 12-week supplementation period, subjects came to the laboratory in the morning (07.00 to 09.00 hours) after an overnight fast to donate blood samples. Blood samples were taken from an antecubital vein with subjects in a seated position. Plasma quercetin levels and leucocyte subset cell counts were analysed for all samples. NKCA and lymphocyte subsets were analysed for seventy-four subjects, and GOBA and phagocytosis were assessed in sixty-four subjects. There was some overlap between the cohorts: eighteen subjects were tested for both NKCA and GOBA/phagocytosis. 


\section{Plasma quercetin}

Total plasma quercetin (quercetin and its primary conjugates) was measured following solid-phase extraction via reversedphase HPLC with UV detection as previously described ${ }^{(30,31)}$. Quercetin conjugates were hydrolysed by incubating $500 \mu 1$ plasma samples with $10 \mu 110 \%$ DL-dithiothreitol solution, $50 \mu 1$ $0.58 \mathrm{M}$-acetic acid, $50 \mu \mathrm{l}$ of a mixture of $\beta$-glucuronidasearylsulfatase and crude extract from Helix pomatia (Roche Diagnostics Corporation, Indianapolis, IN, USA) for $2 \mathrm{~h}$ at $37^{\circ} \mathrm{C}$. Chromatographic analysis was performed using the Ultimate 3000 HPLC-PDA system (Dionex Corporation, Sunnyvale, CA, USA) with a Gemini C18 column (Phenomenex, Torrance, CA, USA). Three quality control samples, using human plasma samples spiked with quercetin at concentrations of $1 \cdot 0,1.5$ and $3.0 \mu \mathrm{mol} / 1$, were assayed in duplicate, with an intra-assay $\mathrm{CV}$ of $12 \cdot 5 \%$.

\section{Leucocyte differential}

A complete blood count with leucocyte differential was analysed in the clinical laboratory of the Watauga Medical Center (Boone, NC, USA) using standard clinical laboratory equipment and quality standards.

\section{Plasma IL-6 and TNF- $\alpha$}

High-sensitivity ELISA kits were used to measure total plasma concentrations of IL- 6 and TNF- $\alpha$ in accordance with the manufacturer's protocol (R\&D Systems, Inc., Minneapolis, MN, USA). All samples and provided standards were analysed in duplicate. The minimum detectable concentrations of IL-6 and $\mathrm{TNF}-\alpha$ were $<0.039 \mathrm{pg} / \mathrm{ml}$ and $<0.106 \mathrm{pg} / \mathrm{ml}$, respectively. Pre- and post-supplementation samples were analysed on the same assay plate to decrease interkit assay variability, and the intra-assay CV for all variables was less than $10 \%$. Data were analysed with SOFTmax software (Molecular Devices, Sunnyvale, CA, USA).

\section{Lymphocyte subsets}

Lymphocyte subset data $(\% \mathrm{~T}, \% \mathrm{~B}$ and $\% \mathrm{NK})$ were obtained by flow cytometry. Briefly, peripheral blood mononuclear cells were isolated from heparinised whole blood by density gradient centrifugation with Fico/Lite. The cells were washed twice and re-suspended to $1 \mathrm{ml}$ in Roswell Park Memorial Institute (RPMI)-1640 supplemented with $10 \%$ heat-inactivated fetal calf serum, penicillin, streptomycin and L-glutamine (complete-RPMI). A sample $(100 \mu \mathrm{l})$ of cells was removed and stained for $15 \mathrm{~min}$ with $10 \mu \mathrm{l}$ CYTO$\mathrm{STAT}^{\circledR}$ tetraCHROME ${ }^{\mathrm{TM}}$. In addition to CD45-fluorescein isothiocyanate (FIFC), the fluorescent conjugates used were as follows: CD56-phycoerythrin (RD1), CD19-phycoerythrinTexas-Red ${ }^{\circledR}-\mathrm{X}$ (ECD) and CD3-phycoerythrin-Cy5 (PC5) (Beckman Coulter, Fullerton, CA, USA). CYTOSTAT ${ }^{\circledR}$ tetra$\mathrm{CHROME}^{\mathrm{TM}}$ is a combination of four murine monoclonal antibodies, each conjugated to a specific fluorochrome, used to differentiate lymphocyte subsets based on their cell surface markers. The lymphocytes were gated using intracellular complexity (side scatter) and FITC fluorescence intensity $\left(\mathrm{CD} 45^{+}\right)$, and flow cytometric dot plots of CD19-ECD $v$.
CD3-PC5 and CD56-RD1 v. CD3-PC5 were produced. In this manner, the percentage of lymphocytes that were NK cells $\left(\mathrm{CD}_{5} 6^{+} \mathrm{CD}^{-}\right)$, B-cells $\left(\mathrm{CD} 19^{+} \mathrm{CD}^{-}\right)$and T-cells $\left(\mathrm{CD}^{+}\right.$ $\mathrm{CD} 19^{-}$) was determined for each subject. Absolute numbers of each cell type were then calculated using the complete blood count data to allow group comparison of circulating cell counts.

\section{Natural killer cell activity assay}

NKCA was assessed using a modification of a flow cytometric assay $^{(24,32)}$. Peripheral blood mononuclear cells (effector cells) were isolated from heparinised blood by density gradient centrifugation with Fico/Lite, washed twice, and re-suspended to $3.75 \times 10^{6}$ cells $/ \mathrm{ml}$. K562 cells in log phase (target cells, $1 \times 10^{6}$ cells $/ \mathrm{ml}$ ) were labelled for $20 \mathrm{~min}$ at $37^{\circ} \mathrm{C}$ in $5 \%$ $\mathrm{CO}_{2}$ with $10 \mu \mathrm{l} 3 \mathrm{~mm}$-DiO solution (3,3'-dioctadecyloxacarbocyanine perchlorate (Sigma Chemical Co., St Louis, MO, USA) in dimethylsulfoxide) per $1 \mathrm{ml}$ cell suspension. After labelling, the target cells were washed and re-suspended in complete-RPMI to a concentration of $5 \times 10^{5}$ cells $/ \mathrm{ml}$. Effector and target cells were combined in four $15 \times 75 \mathrm{~mm}$ $(5 \mathrm{ml})$ tubes to yield effector:target ratios of $60: 1,30: 1,15: 1$ and 7.5:1 with final volumes of $0.9 \mathrm{ml}$. Given the proven reproducibility, high sensitivity and large number of cells used in this flow cytometric assay, a single assay tube was used for each effector:target ratio ${ }^{(32)}$. Control tubes received target cells with no effectors. All tubes received $0.1 \mathrm{ml}$ of a solution of propidium iodide $(500 \mu \mathrm{g} / \mathrm{ml}$; Sigma Chemical Co., St Louis, MO, USA) in RPMI, after which the tubes were vortexed, pelleted by centrifugation for $2 \mathrm{~min}$ at $1200 \mathrm{rpm}$, and incubated for $2 \mathrm{~h}$ at $37^{\circ} \mathrm{C}$ in $5 \% \mathrm{CO}_{2}$. Following incubation, the tubes were vortexed briefly, placed in an ice-water-bath and analysed by flow cytometry within $45 \mathrm{~min}$. Analyses of samples were performed using a Beckman Coulter FC-500 flow cytometer with CXP software (Fullerton, CA, USA). DiO-labelled target cells emit a green fluorescence that can be detected on fluorescence channel 1 and compromised cells that have taken up propidium iodide emit a red fluorescence that can be detected on fluorescence channel 3. The percentage of target cells that were compromised was determined for each tube. The results were acceptable if the spontaneous lysis of target cells (percentage non-viable target cells in the control tube) was $\leq 5 \%$. NK cell-induced lysis of target cells was determined by subtracting the spontaneous lysis of target cells from the percentage of non-viable target cells in tubes containing both effectors and targets at each effector:target ratio. Results were normalised by conversion to lytic units, calculated as the number of effector cells required to lyse $20 \%$ of 5000 target cells, and reported as the number of lytic units contained in $10^{7}$ cells $^{(33)}$.

\section{Measurement of granulocyte phagocytosis and oxidative burst activity}

Simultaneous measurement of granulocyte phagocytosis and oxidative burst activity was performed using a modified flow cytometric assay $^{(34)}$. For each sample, $100 \mu$ l heparinised whole blood were dispensed into two $15 \times 75 \mathrm{~mm}(5 \mathrm{ml})$ tubes. To each tube, $10 \mu \mathrm{l}$ hydroethidine working solution (10 $\mu \mathrm{g}$ hydroethidine/ml in PBS-glucose; Invitrogen Corporation, Carlsbad, CA, USA) were added. The tubes were 
vortexed briefly, incubated in a $37^{\circ} \mathrm{C}$ water-bath for $15 \mathrm{~min}$, and cooled in a $4^{\circ} \mathrm{C}$ ice-water-bath for $12 \mathrm{~min}$. After the hydroethidine-loaded blood samples were cooled, $20 \mu \mathrm{l}$ of working bacteria-FITC solution (Staphylococcus aureus labelled with FITC, diluted in PBS to $1.33 \times 10^{8}$ particles/ $\mathrm{ml}$; Invitrogen Corporation, Carlsbad, CA, USA) were added to both tubes and vortexed briefly. Tube 2 (test) was transferred to a $37^{\circ} \mathrm{C}$ water-bath, and tube 1 (control) was left in the ice. The tubes were incubated for $20 \mathrm{~min}$, placed in an ice-water-bath, and $100 \mu \mathrm{l}$ ice-cold Quench Solution (0.025\% Trypan blue in $0.1 \mathrm{M}$-citrate buffer, $\mathrm{pH} 4.0)$ were added to each tube. The tubes were vortexed for $10 \mathrm{~s}$ and incubated for $1 \mathrm{~min}$ to quench the FITC fluorescence of any noninternalised bacteria, after which the cells were washed twice with ice-cold PBS and re-suspended in $50 \mu$ l cold fetal bovine serum. Samples were processed on a Q-Prep ${ }^{\text {TM }}$ Workstation (Beckman Coulter, Inc., Fullerton, CA, USA), which lysed the erythrocytes and stabilised and fixed the leucocytes. Tubes were stored at room temperature in the dark until flow cytometric analysis, which was performed within $24 \mathrm{~h}$ of blood collection for all samples.

Analysis of samples was performed using a Beckman Coulter FC-500 flow cytometer with CXP software (Fullerton, CA, USA). FITC emits a green fluorescence; therefore, cells that phagocytose the FITC-labelled bacteria are detected as fluorescence channel 1-positive. Similarly, cells stimulated by the bacteria will undergo a respiratory burst, oxidising the non-fluorescent hydroethidine to ethidium bromide, which emits a red fluorescence that can be detected on fluorescence channel 3. After gating on the granulocytes using forward scatter and side scatter, the mean fluorescence intensity (x-mean) for each channel was determined and shifts in $\mathrm{x}$-mean were calculated by subtracting the control $\left(4^{\circ} \mathrm{C}\right)$ $\mathrm{x}$-mean from the test $\left(37^{\circ} \mathrm{C}\right) \mathrm{x}$-mean for fluorescence channel 1 and fluorescence channel 3. Typically, 5000 granulocytes were counted for each reaction tube. The mean intra-assay $\mathrm{CV}$ was $<7 \%$ for phagocytosis and $<10.5 \%$ for GOBA.

\section{Statistical analysis}

All statistical analyses were performed using SPSS PC version 16.0 software (SPSS Inc., Chicago, IL, USA). Data are expressed as mean values with their standard errors. Data were analysed using a 3 (group) $\times 2$ (time) repeated-measures ANOVA, between-groups design, with post hoc analysis using independent $t$ tests that contrasted pre-to-postsupplementation changes of Q-500 and Q-1000 with placebo. Self-reported fitness levels, BMI, body composition and lifestyle data were correlated with NKCA using Pearson correlations. Subject characteristics were contrasted between groups using one-way ANOVA. For all tests, $P<0.05$ was considered significant.

\section{Results}

\section{Subject characteristics}

Subjects were Caucasian females, aged 30-79 years, with a large variance in body mass and composition (Table 1). No changes in body mass and composition were noted over the course of the study, and interaction effects indicated
Table 1. Subject characteristics*

(Mean values with their standard errors)

\begin{tabular}{|c|c|c|c|c|c|c|c|}
\hline & \multicolumn{2}{|c|}{$\begin{array}{c}\text { Placebo } \\
(n \text { 42) }\end{array}$} & \multicolumn{2}{|c|}{$\begin{array}{l}\text { Q-500 } \\
(n 38)\end{array}$} & \multicolumn{2}{|c|}{$\begin{array}{l}\text { Q-1000 } \\
(n 40)\end{array}$} & \multirow[b]{2}{*}{ ANOVA: $P$} \\
\hline & Mean & SEM & Mean & SEM & Mean & SEM & \\
\hline Age (years) & 47.0 & $1 \cdot 1$ & $45 \cdot 4$ & $1 \cdot 1$ & $47 \cdot 4$ & $1 \cdot 3$ & 0.459 \\
\hline Height $(\mathrm{m})$ & 1.65 & 0.01 & 1.64 & 0.01 & 1.64 & 0.01 & 0.940 \\
\hline Weight (kg) & $72 \cdot 2$ & 2.9 & 71.3 & 2.5 & 71.7 & 3.4 & 0.979 \\
\hline BMI $\left(\mathrm{kg} / \mathrm{m}^{2}\right)$ & $26 \cdot 6$ & 1.0 & $26 \cdot 4$ & 0.9 & $26 \cdot 6$ & 1.2 & 0.994 \\
\hline Body fat (\%) & 34.5 & 1.7 & 35.3 & 1.5 & 34.3 & 1.6 & 0.896 \\
\hline
\end{tabular}

Q-500, $500 \mathrm{mg}$ quercetin/d; Q-1000, $1000 \mathrm{mg}$ quercetin/d.

* The study population was 120 females aged $30-79$ years.

no group differences (data not shown). With all subjects combined, no significant correlations were found between subject age and any of the pre-study measures of innate immune function (all $P>0 \cdot 4$ ) or inflammation (all $P>0 \cdot 2$ ).

\section{Plasma quercetin}

Plasma quercetin increased significantly above placebo levels after the 12-week supplementation with 500 or $1000 \mathrm{mg}$ aglycone quercetin/d (group $\times$ time interaction effect; $P<0.001$ ) (Fig. 1). No significant correlations were found between plasma quercetin levels and dietary variables (data not shown).

\section{Leucocyte subsets}

The pattern of change over time was not significantly different between groups for total leucocytes $(P=0 \cdot 306)$, total lymphocytes $(P=0 \cdot 867)$ or neutrophil counts $(P=0 \cdot 193)$ (Table 2$)$.

\section{Plasma IL-6 and TNF- $\alpha$}

The 12 -week quercetin supplementation at 500 or $1000 \mathrm{mg} / \mathrm{d}$ had no effect on plasma concentrations of IL-6 $(P=0.812)$ or TNF- $\alpha(P=0.208)$ (Table 2$)$. For all subjects combined, a positive correlation was found between BMI and IL-6 ( $r$ 0.23; $P=0.010$ ), whereas the relationship between BMI and TNF- $\alpha$ did not reach significance $(r 0 \cdot 131 ; P=0 \cdot 153)$.

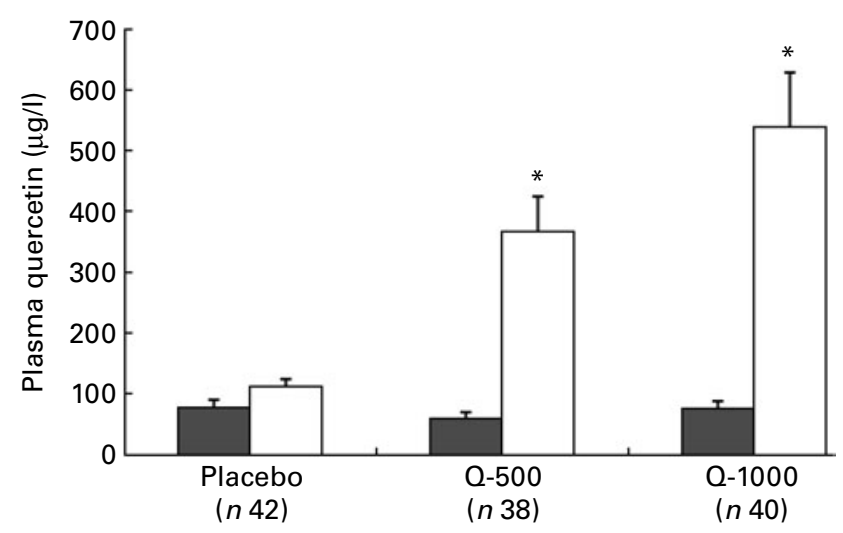

Fig. 1. Plasma quercetin levels at baseline $(\square)$ and after 12 weeks of supplementation $(\square)$ with quercetin at $500 \mathrm{mg} / \mathrm{d}(\mathrm{Q}-500)$ or $1000 \mathrm{mg} / \mathrm{d}(\mathrm{Q}-1000)$ compared with placebo $(n 120)$. Values are means, with standard errors represented by vertical bars. There was a group $\times$ time interaction $(P<0.001)$. ${ }^{\star}$ Significant change from pre-study compared with placebo $(P \leq 0.05)$. 
Table 2. Blood leucocyte subset cell counts and plasma inflammatory markers at baseline and after 12 weeks of supplementation with quercetin at $500 \mathrm{mg} / \mathrm{d}(\mathrm{Q}-500)$ or $1000 \mathrm{mg} / \mathrm{d}$ (Q-1000) compared with placebo*

(Mean values with their standard errors)

\begin{tabular}{|c|c|c|c|c|c|c|c|}
\hline \multirow[t]{2}{*}{ Group... } & \multicolumn{2}{|c|}{ Placebo ( $n$ 42) } & \multicolumn{2}{|c|}{ Q-500 (n 38) } & \multicolumn{2}{|c|}{$\mathrm{Q}-1000(n 40)$} & \multirow[b]{2}{*}{ Interaction: $P$} \\
\hline & Mean & SEM & Mean & SEM & Mean & SEM & \\
\hline \multicolumn{8}{|c|}{ Total leucocytes ( $10^{9} /$ litre) } \\
\hline Pre-study & 5.91 & 0.34 & $5 \cdot 80$ & 0.23 & $5 \cdot 78$ & 0.26 & \multirow{2}{*}{0.306} \\
\hline Post-study & 5.75 & 0.29 & 5.94 & 0.25 & 5.98 & 0.31 & \\
\hline \multicolumn{8}{|c|}{ Neutrophils ( $10^{9} /$ litre) } \\
\hline Pre-study & 3.41 & 0.24 & 3.50 & $0 \cdot 19$ & $3 \cdot 21$ & 0.20 & \multirow{2}{*}{0.193} \\
\hline Post-study & $3 \cdot 28$ & 0.21 & 3.63 & 0.20 & 3.48 & 0.24 & \\
\hline \multicolumn{8}{|c|}{ Lymphocytes ( $10^{9} /$ litre) } \\
\hline Pre-study & $1 \cdot 81$ & 0.09 & $1 \cdot 71$ & 0.07 & 1.87 & 0.09 & \multirow{2}{*}{0.867} \\
\hline Post-study & 1.81 & 0.09 & $1 \cdot 71$ & 0.08 & 1.84 & 0.10 & \\
\hline \multicolumn{8}{|c|}{ Plasma IL-6 (pg/ml) } \\
\hline Pre-study & 1.72 & 0.18 & 1.64 & $0 \cdot 19$ & $2 \cdot 38$ & 0.78 & \multirow{2}{*}{0.812} \\
\hline Post-study & 1.76 & 0.20 & 1.84 & 0.25 & 2.58 & 0.96 & \\
\hline \multicolumn{8}{|c|}{ Plasma TNF- $\alpha$ (pg/ml) } \\
\hline Pre-study & 1.19 & 0.10 & 1.59 & 0.22 & 1.22 & 0.17 & \multirow{2}{*}{0.208} \\
\hline Post-study & 1.24 & $0 \cdot 10$ & 1.39 & 0.19 & 1.24 & 0.17 & \\
\hline
\end{tabular}

* Pre- and post-study blood samples were obtained from all subjects $(n 120)$ after an $8 \mathrm{~h}$ fast.

\section{Granulocyte oxidative burst activity and phagocytosis}

The pattern of change over time was not significantly different between groups for granulocyte respiratory burst activity $(P=0.602)$ or phagocytosis $(P=0.990)$ (Figs. 2 and 3). No correlations were found between any outcome measures and GOBA or phagocytosis. For all subjects combined, GOBA increased pre- to post-supplementation $(P<0 \cdot 001)$.

\section{Lymphocyte subsets}

Circulating counts of $\mathrm{B}, \mathrm{T}$ or NK cells were not influenced by 12 -week supplementation with quercetin at 500 or $1000 \mathrm{mg} / \mathrm{d}$ (Table 3).

\section{Natural killer cell activity}

Pre- and post-supplementation data for percentage lysis of K562 target cells by NK cells showed no significant

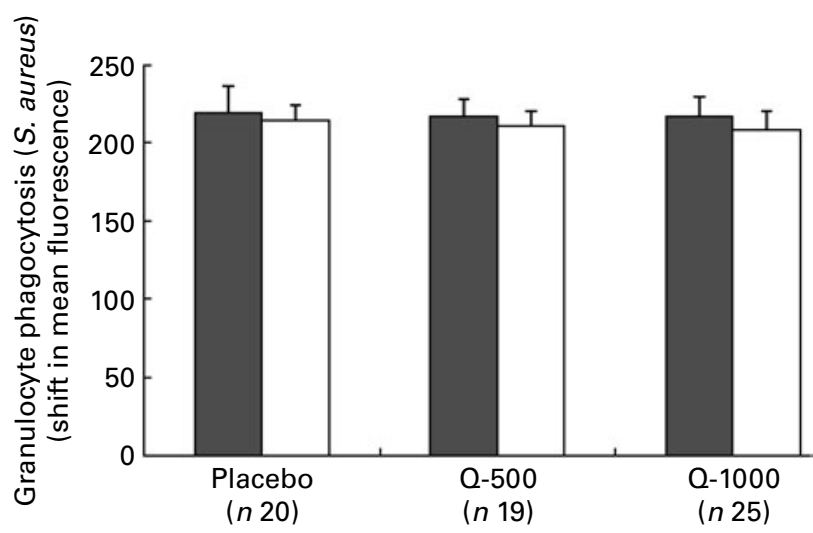

Fig. 2. Granulocyte phagocytosis of fluorescein isothiocyanate (FITC)-labelled Staphylococcus aureus at baseline $(\square)$ and after 12 weeks of supplementation $(\square)$ with quercetin at $500 \mathrm{mg} / \mathrm{d}$ (Q-500) or $1000 \mathrm{mg} / \mathrm{d}$ (Q-1000) compared with placebo. Data are expressed as shifts in mean FITC fluorescence from $4^{\circ} \mathrm{C}$ to $37^{\circ} \mathrm{C}(n 64)$. Values are means, with standard errors represented by vertical bars. There was no group $\times$ time interaction $(P=0.990)$. differences between groups across all effector:target ratios (Table 4). The pattern of change over time for total lytic activity of NK cells was not significantly different between treatment groups $(P=0.696)$ (Fig. 4). Although NKCA tended to increase pre- to post-supplementation for all subjects combined, this apparent time effect did not reach significance $(P=0 \cdot 163)$. When pre- and post-study measures were averaged for all subjects combined $(n$ 74), NKCA was correlated positively with self-reported physical fitness level $(r$ 0.24; $P=0.032)$ and negatively with BMI $(r-0.25 ; P=0.035)$ and body fat percentage $(r-0.38 ; P=0 \cdot 001)$ (Fig. 5$)$.

\section{Discussion}

This is the first human clinical trial to investigate the longterm effects of aglycone quercetin supplementation on measures of innate immune function and inflammation in adult female subjects recruited from the community. These subjects tended to be overweight individuals (mean

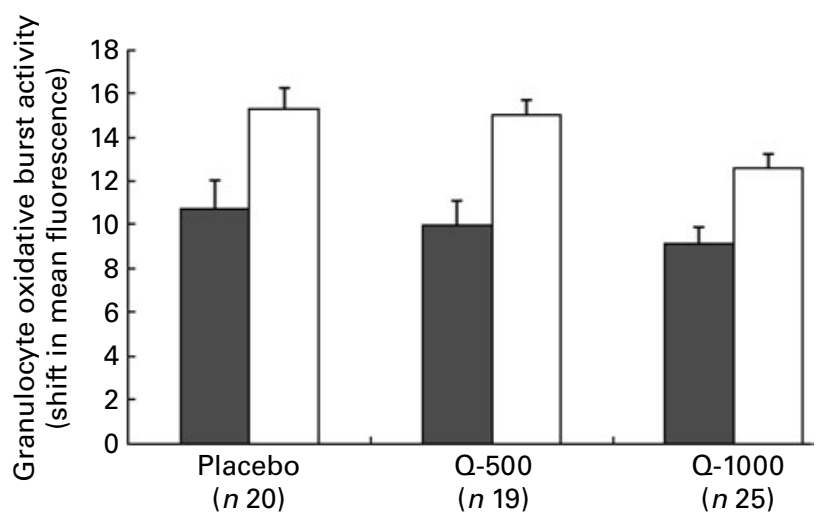

Fig. 3. Granulocyte oxidative burst activity following incubation with Staphylococcus aureus at baseline $(\square)$ and after 12 weeks of supplementation ( $\square$ ) with quercetin at $500 \mathrm{mg} / \mathrm{d}(\mathrm{Q}-500)$ or $1000 \mathrm{mg} / \mathrm{d}(\mathrm{Q}-1000)$ compared with placebo. Data are expressed as shifts in mean ethidium bromide fluorescence from $4^{\circ} \mathrm{C}$ to $37^{\circ} \mathrm{C}(n 64)$. Values are means, with standard errors represented by vertical bars. There was no group $\times$ time interaction $(P=0.602)$. 
Table 3. Blood lymphocyte subset cell counts for subjects with natural killer cell activity data $(n 74)$ at baseline and after 12 weeks of supplementation with quercetin at $500 \mathrm{mg} / \mathrm{d}(\mathrm{Q}-500)$ or $1000 \mathrm{mg} / \mathrm{d}(\mathrm{Q}-1000)$ compared with placebo* (Mean values with their standard errors)

\begin{tabular}{|c|c|c|c|c|c|c|c|}
\hline \multirow[t]{2}{*}{ Group... } & \multicolumn{2}{|c|}{ Placebo ( $n$ 26) } & \multicolumn{2}{|c|}{ Q-500 (n 24) } & \multicolumn{2}{|c|}{ Q-1000 (n 24) } & \multirow[b]{2}{*}{ Interaction: $P$} \\
\hline & Mean & SEM & Mean & SEM & Mean & SEM & \\
\hline \multicolumn{8}{|c|}{ T lymphocytes ( $10^{9} /$ litre) } \\
\hline Pre-study & 1.42 & 0.08 & 1.33 & 0.09 & 1.47 & 0.08 & \multirow{2}{*}{0.999} \\
\hline Post-study & 1.41 & 0.09 & 1.32 & 0.09 & 1.46 & $0 \cdot 10$ & \\
\hline \multicolumn{8}{|c|}{ B lymphocytes ( $10^{9} /$ litre) } \\
\hline Pre-study & 0.24 & 0.03 & 0.22 & 0.02 & 0.23 & 0.03 & \multirow{2}{*}{0.603} \\
\hline Post-study & 0.25 & 0.02 & 0.22 & 0.02 & 0.25 & 0.04 & \\
\hline \multicolumn{8}{|c|}{ Natural killer lymphocytes ( $10^{9} /$ litre) } \\
\hline Pre-study & 0.20 & 0.02 & 0.16 & 0.02 & 0.18 & 0.02 & \multirow{2}{*}{0.885} \\
\hline Post-study & 0.19 & 0.02 & 0.15 & 0.02 & 0.18 & 0.02 & \\
\hline
\end{tabular}

*Pre- and post-study blood samples were analysed for lymphocyte subsets using flow cytometry.

BMI $>25 \cdot 0 \mathrm{~kg} / \mathrm{m}^{2}$ ) with mean pre-study plasma IL-6 and $\mathrm{TNF}-\alpha$ concentrations that were slightly elevated compared with values reported for lean, healthy women in other studies $^{(35,36)}$. The data indicate that the 12-week supplementation with 500 or $1000 \mathrm{mg}$ quercetin/d was not associated with changes in NKCA, GOBA, phagocytosis, or plasma IL- 6 and TNF- $\alpha$ in this population.

Quercetin is a powerful antioxidant ${ }^{(3)}$ that exerts in vitro anti-inflammatory effects via inhibition of NF- $\mathrm{B}$ signalling in a variety of cells including macrophages and peripheral blood mononuclear cells ${ }^{(5,6)}$. Homo- and heterodimers of $\mathrm{NF}-\kappa \mathrm{B}$ are located in the cytoplasm of unstimulated immune cells, where they are tightly bound to IкB inhibitory proteins $^{(6)}$. When immune cells are stimulated, the IкB proteins are phosphorylated, ubiquitylated and degraded, freeing the NF- $\mathrm{BB}$ dimers for translocation to the nucleus, where they can bind to the promoter regions of genes involved in the inflammatory response. Quercetin appears to exert in vitro anti-inflammatory effects via inhibition of I $\mathrm{B}$ phosphorylation $^{(6)}$. Binding sites for $N F-\kappa B$ proteins have been found in the promoter regions of the genes that code for both
TNF- $\alpha$ and IL-6, and studies have shown that IL-6 mRNA production does not occur in the absence of activated $\mathrm{NF}-\mathrm{\kappa B}^{(37,38)}$. Despite its known anti-inflammatory properties, the present study did not find a quercetin-related effect on circulating levels of IL- 6 and TNF- $\alpha$. It should be noted that, although the mean plasma TNF- $\alpha$ and IL- 6 levels of subjects in the present study were slightly elevated compared with those reported for lean females in other studies ${ }^{(35,36)}$, they fell within the normal ranges for adult females ${ }^{(39)}$. The lack of quercetin-related effect on inflammation reported in the present study could be because these subjects were already within normal limits with regard to the outcome measures. Future studies comparing the effects of quercetin supplementation on inflammatory status in normal, overweight and obese subjects would be valuable.

In the present study, quercetin supplementation had no measurable effect on NKCA, GOBA or phagocytosis. A moderate time effect was noted for GOBA, but this could be due to seasonal effects on innate immune function. The post-supplementation blood draw was in November, 12 weeks after the August pre-supplementation blood draw.

Table 4. Natural killer cell activity at baseline and after 12 weeks of supplementation with quercetin at $500 \mathrm{mg} / \mathrm{d}(\mathrm{Q}-500)$ or $1000 \mathrm{mg} / \mathrm{d}(\mathrm{Q}-1000)$ compared with placebo expressed as percentage lysis at four effector:target $(\mathrm{E}: \mathrm{T})$ cell ratios*

(Mean values with their standard errors)

\begin{tabular}{|c|c|c|c|c|c|c|c|}
\hline \multirow{2}{*}{$\begin{array}{l}\text { Group... } \\
\text { E:T ratio }\end{array}$} & \multicolumn{2}{|c|}{ Placebo (n 26) } & \multicolumn{2}{|c|}{ Q-500 (n 24) } & \multicolumn{2}{|c|}{ Q-1000 (n 24) } & \multirow[b]{2}{*}{ Interaction: $P$} \\
\hline & Mean & SEM & Mean & SEM & Mean & SEM & \\
\hline \multicolumn{8}{|l|}{ 60:1 (\% lysis) } \\
\hline Pre-study & $43 \cdot 5$ & 3.4 & $36 \cdot 6$ & $3 \cdot 3$ & $40 \cdot 8$ & $2 \cdot 8$ & \multirow{2}{*}{0.582} \\
\hline Post-study & $47 \cdot 2$ & $3 \cdot 1$ & $44 \cdot 0$ & 3.6 & $49 \cdot 1$ & 3.2 & \\
\hline \multicolumn{8}{|l|}{ 30:1 (\% lysis) } \\
\hline Pre-study & 37.9 & 3.0 & $32 \cdot 3$ & 3.3 & $35 \cdot 6$ & $2 \cdot 8$ & \multirow{2}{*}{0.659} \\
\hline Post-study & $42 \cdot 7$ & $3 \cdot 0$ & 37.5 & 3.4 & $43 \cdot 6$ & $3 \cdot 3$ & \\
\hline \multicolumn{8}{|l|}{ 15:1 (\% lysis) } \\
\hline Pre-study & $29 \cdot 2$ & 2.5 & $24 \cdot 3$ & 3.0 & $28 \cdot 3$ & 2.9 & \multirow{2}{*}{0.943} \\
\hline Post-study & $32 \cdot 6$ & $2 \cdot 6$ & $27 \cdot 8$ & $2 \cdot 8$ & $32 \cdot 6$ & 3.0 & \\
\hline \multicolumn{8}{|l|}{ 7.5:1 (\% lysis) } \\
\hline Pre-study & $19 \cdot 9$ & $1 \cdot 8$ & $17 \cdot 0$ & $2 \cdot 3$ & $20 \cdot 1$ & $2 \cdot 5$ & \multirow[t]{2}{*}{0.950} \\
\hline Post-study & $22 \cdot 6$ & 1.9 & $19 \cdot 8$ & $2 \cdot 2$ & $22 \cdot 2$ & $2 \cdot 4$ & \\
\hline
\end{tabular}

*Natural killer cells (effectors) were incubated with K562 cells (targets) and analysed by flow cytometry for seventy-four subjects; percentage non-spontaneous lysis of target cells at each E:T ratio is presented here. 


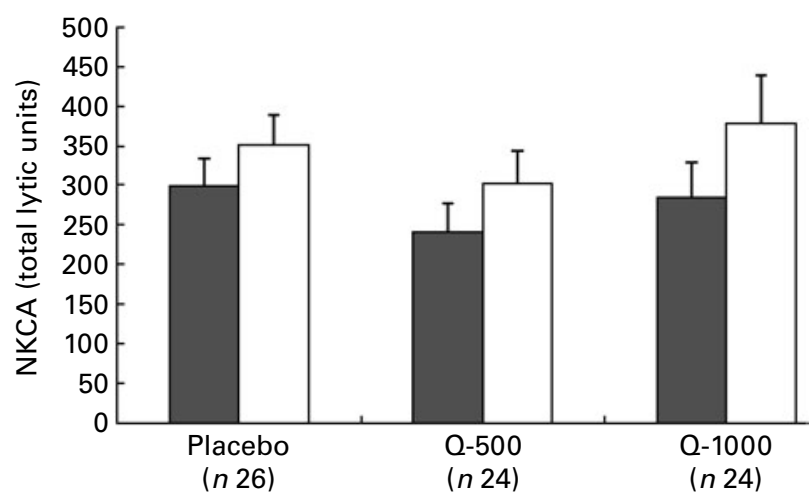

Fig. 4. Natural killer (NK) cell activity (NKCA) of human subjects at baseline $(\square)$ and after 12 weeks of supplementation $(\square)$ with quercetin at $500 \mathrm{mg} / \mathrm{d}$ $(\mathrm{Q}-500)$ or $1000 \mathrm{mg} / \mathrm{d}(\mathrm{Q}-1000)$ compared with placebo $(n 74)$. NKCA is expressed as the number of lytic units contained in $10^{7}$ cells, where a lytic unit is defined as the number of NK cells required to lyse $20 \%$ of $5000 \mathrm{~K} 562$ target cells. Values are means, with standard errors represented by vertical bars. There was no group $\times$ time interaction $(P=0.696)$.

Similar circannual rhythms in immune function have been observed in previous studies performed by our laboratory ${ }^{(40,41)}$. Nonetheless, the pattern of change over time was not significantly different between treatment groups for any measure of immune function. These findings are consistent with studies previously conducted in our laboratory investigating the effects of short-term quercetin supplementation on similar measures of innate immune function in athletes ${ }^{(23,24)}$, but they are contrary to the results of quercetin studies utilising rodent models and in vitro study designs ${ }^{(16,18,19)}$. A study by Exon et al. showed that rats fed quercetin dihydrate for 7 weeks had significantly elevated NKCA compared with controls $^{(19)}$. Both NKCA and the phagocytic activity of peritoneal macrophages were higher in $\mathrm{BALB} / \mathrm{c}$ mice that were treated with quercetin for 3 weeks following injection with WEHI-3 leukaemia cells compared with mice that did not receive quercetin in a recent study by $\mathrm{Yu}$ et al. ${ }^{(18)}$. Akbay et al. found that quercetin glycosides increased the intracellular killing activity of human neutrophils in vitro ${ }^{(16)}$. However, these human and animal studies may not be comparable for a number of reasons. For example, the Exon et al. study used a larger dosage of quercetin $(100 \mathrm{mg} / \mathrm{kg})$ compared with the present study, which supplemented with average daily

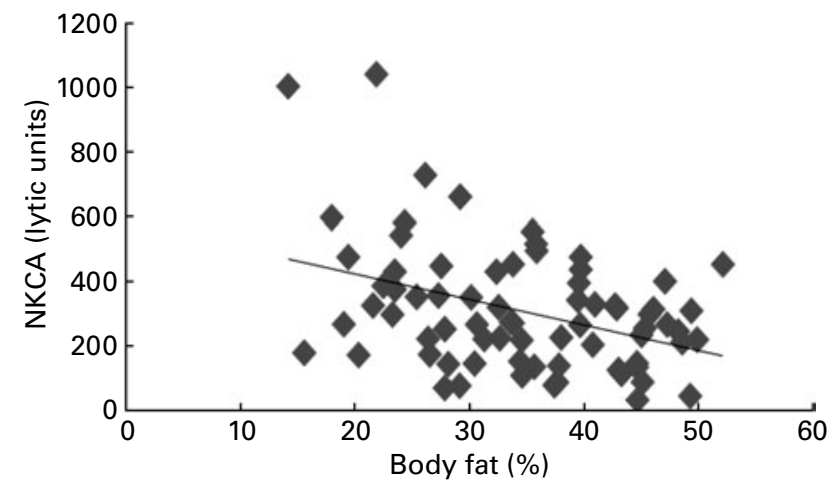

Fig. 5. Relationship between body fat percentage and natural killer cell activity (NKCA) of human subjects $(r-0.38 ; P=0.001)$. Data points average pre- and post-study measures for all subjects with NKCA data $(n 74)$. doses of 7 and $14 \mathrm{mg}$ quercetin/kg for Q-500 and Q-1000 ${ }^{(19)}$. The dosages used in the $\mathrm{Yu}$ et al. study were smaller (2 and $4 \mathrm{mg} / \mathrm{kg}$ ), but the relevance of their results is confounded by the lack of a quercetin-treated group not injected with WEHI-3 cells ${ }^{(18)}$. Finally, data from animal studies attributing an immunomodulatory effect to quercetin supplementation may not be applicable to humans because of possible species-dependent variations in phase II metabolism ${ }^{(42)}$.

Aglycone quercetin supplementation may lack an antiinflammatory or immunomodulatory effect in humans due to either its reduced bioavailability or its metabolic transformation in vivo. Quercetin is found in fruits and vegetables in a water-soluble form in which the quercetin molecule is conjugated to a sugar ${ }^{(2)}$. The in vitro study conducted by Akbay et al. showed that neutrophil intracellular killing activity was increased by incubation with quercetin in such a glycosylated form ${ }^{(16)}$. However, when quercetin is consumed, the sugar is cleaved off in the small intestine, allowing the lipid-soluble aglycone form of quercetin to passively diffuse into the cells lining the intestinal wall ${ }^{(43)}$. In the liver, aglycone quercetin is either methylated, sulfated or glucuronidated. Quercetin predominately circulates in the bloodstream in these conjugate forms, which differ not only from aglycone quercetin, but also from the glycosylated forms found in plant foods. Relatively few studies have examined the bioactivity of quercetin conjugates ${ }^{(44)}$ and further work in this area is indicated.

While supplementation with aglycone quercetin appears to have no effect on NKCA or granulocyte cell function in human subjects, quercetin may exhibit an immunostimulatory effect when ingested in other forms or in combination with other flavonoids. A recent human study found that 4 weeks of supplementation with a fermented food rich in quercetin and other flavonoids significantly increased activation of NK cell cytotoxicity in response to IL-2 stimulation, but did not influence basal (non-stimulated) $\mathrm{NKCA}^{(45)}$. Supplementation with polyphenol-rich cereal fractions has been shown to increase basal NKCA in prematurely ageing mice, in addition to augmenting macrophage phagocytosis and reactive oxygen species production ${ }^{(46)}$. Our laboratory recently found that a 2-week supplementation with a combination of quercetin, epigallocatechin 3-gallate, isoquercetin and n-3 PUFA increased GOBA and decreased post-exercise plasma concentration of IL- $6^{(31)}$. Future research will examine the combined supplements' potential effects on NKCA and phagocytosis. It may also be helpful to investigate whether IL-2-stimulated NK cell lytic activity in human subjects is affected by quercetin supplementation, alone or in combination with other flavonoids.

In the present study, we found that total NK cell lytic activity was related inversely to BMI and body fat percentage, and positively with self-reported fitness level. These findings are consistent with previous studies linking NK cell function with physical fitness and healthy lifestyles ${ }^{(47,48)}$. A crosssectional comparison between marathon runners and sedentary controls found that the marathoners had significantly greater NKCA than the controls, and that percentage body fat was negatively correlated with NKCA for all subjects combined $^{(47)}$. In addition to physical exercise, other lifestyle factors such as not smoking and eating a balanced diet have been associated with elevated numbers of NK cells and 
enhanced NKCA, possibly due to an increased percentage of NK cells expressing perforin, granulysin, and granzymes A and B in subjects with good health practices ${ }^{(48)}$. This suggests that optimisation of NK cell function can be achieved through the maintenance of a healthy lifestyle.

In summary, 12-week aglycone quercetin supplementation in doses of 500 and $1000 \mathrm{mg} / \mathrm{d}$ had no effect on leucocyte subset counts, plasma IL- 6 or TNF- $\alpha$ concentration, NKCA, GOBA or granulocyte phagocytosis relative to placebo. A growing body of evidence indicates that a mixed flavonoid approach to modifying innate immunity is more effective than supplementation with a pure flavonoid such as aglycone quercetin. In athletes, a quercetin supplement combined with epigallocatechin 3-gallate, isoquercetin, and n-3 PUFA significantly reduced post-exercise inflammation and augmented neutrophil function ${ }^{(31)}$. Future research will determine if the immunomodulatory effects of quercetin can be enhanced through the addition of other flavonoids (for example, epigallocatechin 3-gallate) or food components.

\section{Acknowledgements}

The present study was supported by grants from Coca-Cola and Quercegen Pharma. S. A. H., D. A. H. and D. C. N. designed the research and wrote the paper; D. C. N. analysed the data and had primary responsibility for the final content. All authors conducted research and read and approved the final manuscript. The authors would like to thank Krista Kennerly, Ashley Williams, Kendra Maxwell, Patrick O'Reilly, Jackie Hellwege, Ada Bamford Young and Katelyn Graeme for their invaluable assistance with this project.

S. A. H., D, A. H., M, D. A. and F. J. declare no conflicts of interest. D. C. N. holds a position on the science advisory board for Quercegen Pharma.

\section{References}

1. United States Department of Agriculture (2007) USDA Database for the Flavonoid Content of Selected Foods, Release 2.1. http:// www.ars.usda.gov/SP2UserFiles/Place/12354500/Data/Flav/Flav 02-1.pdf (accessed 1 October 2009).

2. Manach C, Williamson G \& Morand C (2005) Bioavailability and bioefficacy of polyphenols in humans. I. Review of 97 bioavailability studies. Am J Clin Nutr 81, Suppl., 230S-242S.

3. Č́íz M, Pavelková M, Gallová L, et al. (2008) The influence of wine polyphenols on reactive oxygen and nitrogen species production by murine macrophages RAW 264.7. Physiol Res 57, 393-402.

4. Dias AS, Porawski M, Alonso M, et al. (2005) Quercetin decreases oxidative stress, NF- $\mathrm{kB}$ activation, and iNOS overexpression in liver of streptozotocin-induced diabetic rats. J Nutr 135, 2299-2304.

5. Comalada M, Camuesco D, Sierra S, et al. (2005) In vivo quercitrin anti-inflammatory effect involves release of quercetin, which inhibits inflammation through down-regulation of the NF-кB pathway. Eur J Immunol 35, 584-592.

6. Nair MP, Mahajan S, Reynolds JL, et al. (2006) The flavonoid quercetin inhibits proinflammatory cytokine (tumor necrosis factor $\alpha$ ) gene expression in normal peripheral blood mononuclear cells via modulation of the NF- $\mathrm{KB}$ system. Clin Vaccine Immunol 13, 319-328.
7. Vrijsen R, Everaert L \& Boeyé A (1988) Antiviral activity of flavones and potentiation by ascorbate. J Gen Virol 69, $1749-1751$

8. Chiang LC, Chiang W, Liu MC, et al. (2003) In vitro antiviral activities of Caesalpinia pulcherrima and its related flavonoids. J Antimicrob Chemother 52, 194-198.

9. Chun OK, Chung SJ \& Song WO (2007) Estimated dietary flavonoid intake and major food sources of U.S. adults. $J$ Nutr 137, 1244-1252.

10. Sampson L, Rimm E, Hollman PCH, et al. (2002) Flavonol and flavone intakes in US health professionals. J Am Diet Assoc 102, $1414-1420$

11. de Boer VCJ, Dihal AA, van der Woude H, et al. (2005) Tissue distribution of quercetin in rats and pigs. $J$ Nutr 135, $1718-1725$.

12. Harwood M, Danielewska-Nikiel B, Borzelleca JF, et al. (2007) A critical review of the data related to the safety of quercetin and lack of evidence of in vivo toxicity, including lack of genotoxic/carcinogenic properties. Food Chem Toxicol 45, 2179-2205.

13. Utesch D, Feige K, Dasenbrock J, et al. (2008) Evaluation of the potential in vivo genotoxicity of quercetin. Mutat Res $\mathbf{6 5 4}$, $38-44$.

14. Hertog MGL, Feskens EJM, Hollman PCH, et al. (1993) Dietary antioxidant flavonoids and risk of coronary heart disease: the Zutphen Elderly Study. Lancet 342, 1007-1011.

15. Neuhouser ML (2004) Dietary flavonoids and cancer risk: evidence from human population studies. Nutr Cancer 50, 1-7.

16. Akbay P, Basaran AA, Undeger U, et al. (2003) In vitro immunomodulatory activity of flavonoid glycosides from Urtica dioica L. Phytother Res 17, 34-37.

17. Oršolić N \& Bašić I (2005) Water-soluble derivative of propolis and its polyphenolic compounds enhance tumoricidal activity of macrophages. J Ethnopharmacol 102, 37-45.

18. Yu CS, Lai KC \& Yang JS (2010) Quercetin inhibited murine leukemia WEHI-3 cells in vivo and promoted immune response. Phytother Res 24, 163-168.

19. Exon JH, Magnuson BA, South EH, et al. (1998) Dietary quercetin, immune functions and colonic carcinogenesis in rats. Immunopharmacol Immunotoxicol 20, 173-190.

20. Bancroft GJ (1993) The role of natural killer cells in innate resistance to infection. Curr Opin Immunol 5, 503-510.

21. Cooper MA, Fehniger TA \& Caligiuri MA (2001) The biology of human natural killer-cell subsets. Trends Immunol 22, 633-640.

22. Kobayashi SD, Voyich JM, Burlak C, et al. (2005) Neutrophils in the innate immune response. Arch Immunol Ther Exp 53, 505-517.

23. Henson DA, Nieman DC, Davis JM, et al. (2008) Post-160-km race illness rates and decreases in granulocyte respiratory burst and salivary IgA output are not countered by quercetin ingestion. Int J Sports Med 29, 856-863.

24. Nieman DC, Henson DA, Gross SJ, et al. (2007) Quercetin reduces illness but not immune perturbations after intensive exercise. Med Sci Sports Exerc 39, 1561-1569.

25. Koch A, Kunkel S \& Strieter R (1995) Cytokines in rheumatoid arthritis. J Invest Med 43, 28-38.

26. Danesh J, Kaptoge S, Mann AG, et al. (2008) Long-term interleukin-6 levels and subsequent risk of coronary heart disease: two new prospective studies and a systematic review. PLoS Med 5, e78.

27. Egert S, Bosy-Westphal A, Seiberl J, et al. (2009) Quercetin reduces systolic blood pressure and plasma oxidised lowdensity lipoprotein concentrations in overweight subjects with a high-cardiovascular disease risk phenotype: a doubleblinded, placebo-controlled cross-over study. Br J Nutr 102, $1065-1074$. 
28. Davis JM, Murphy EA, Carmichael MD, et al. (2009) Quercetin increases brain and muscle mitochondrial biogenesis and exercise tolerance. Am J Physiol Regul Integr Comp Physiol 296, R1071-R1077.

29. Nieman DC, Henson DA, Davis JM, et al. (2007) Quercetin's influence on exercise-induced changes in plasma cytokines and muscle and leukocyte cytokine mRNA. J Appl Physiol 103, 1728-1735.

30. Nieman DC, Henson DA, Davis JM, et al. (2007) Quercetin ingestion does not alter cytokine changes in athletes competing in the Western States Endurance Run. J Interferon Cytokine Res 27, 1003-1012.

31. Nieman DC, Henson DA, Maxwell KR, et al. (2009) Effects of quercetin and EGCG on mitochondrial biogenesis and immunity. Med Sci Sports Exerc 41, 1467-1475.

32. Chang L, Gusewitch GA, Chritton DBW, et al. (1993) Rapid flow cytometric assay for the assessment of natural killer cell activity. J Immunol Methods 166, 45-54.

33. Bryant J, Day R, Whiteside TL, et al. (1992) Calculation of lytic units for the expression of cell-mediated cytotoxicity. J Immunol Methods 146, 91-103.

34. Perticarari S, Presani G \& Banfi E (1994) A new flow cytometric assay for the evaluation of phagocytosis and the oxidative burst in whole blood. J Immunol Methods 170, $117-124$.

35. Bastard J-P, Jardel C, Bruckert E, et al. (2000) Elevated levels of interleukin- 6 are reduced in serum and subcutaneous adipose tissue of obese women after weight loss. J Clin Endocrinol Metab 85, 3338-3342.

36. Rexrode KM, Pradhan A, Manson JE, et al. (2003) Relationship of total and abdominal adiposity with CRP and IL-6 in women. Ann Epidemiol 13, 674-682.

37. Azzolina A (2003) Substance P induces TNF- $\alpha$ and IL-6 production through NFkB in peritoneal mast cells. Biochim Biophys Acta 1643, 75-83.
38. Marquardt D \& Walker L (2000) Dependence of mast cell IgEmediated cytokine production on nuclear factor- $\kappa \mathrm{B}$ activity. J Allergy Clin Immunol 105, 500-505.

39. Marques-Deak A, Cizza G, Eskandari F, et al. (2006) Measurement of cytokines in sweat patches and plasma in healthy women: validation in a controlled study. J Immunol Methods 315, 99-109.

40. Nieman DC, Henson DA, Gusewitch G, et al. (1993) Physical activity and immune function in elderly women. $\mathrm{Med} \mathrm{Sci}$ Sports Exerc 25, 823-831.

41. Nieman DC, Nehlsen-Cannarella SL, Henson DA, et al. (1996) Immune response to obesity and moderate weight loss. Int $J$ Obesity 20, 353-360.

42. Graf BA, Ameho C, Dolnikowski GG, et al. (2006) Rat gastrointestinal tissues metabolize quercetin. $J$ Nutr 136, 39-44.

43. Nemeth K \& Piskula MK (2007) Food content, processing, absorption and metabolism of onion flavonoids. Crit Rev Food Sci Nutr 47, 397-409.

44. Williamson $\mathrm{G}$, Barron $\mathrm{D}$, Shimoi $\mathrm{K}$, et al. (2005) In vitro biological properties of flavonoid conjugates found in vivo. Free Radical Res 39, 457-469.

45. Schoen C, Schulz A, Schweikart J, et al. (2009) Regulatory effects of a fermented food concentrate on immune function parameters in healthy volunteers. Nutrition 25, 499-505.

46. Álvarez P, Alvarado C, Puerto M, et al. (2006) Improvement of leukocyte functions in prematurely aging mice after five weeks of diet supplementation with polyphenol-rich cereals. Nutrition 22, 913-921.

47. Nieman DC, Buckley KS, Henson DA, et al. (1995) Immune function in marathon runners versus sedentary controls. Med Sci Sports Exerc 27, 986-992.

48. Li Q, Morimoto K, Nakadai A, et al. (2007) Healthy lifestyles are associated with higher levels of perforin, granulysin and granzymes $\mathrm{A} / \mathrm{B}$-expressing cells in peripheral blood lymphocytes. Prev Med 44, 117-123. 